\title{
High-Molecular-Weight Paired Helical Filaments from Alzheimer Brain Induces Seeding of Wild-Type Mouse Tau into an Argyrophilic 4R Tau Pathology in Vivo
}

\author{
Emilie Audouard, * Sarah Houben, * Caterina Masaracchia, * Zehra Yilmaz, ${ }^{*}$ Valérie Suain, * Michèle Authelet, * \\ Robert De Decker, ${ }^{*}$ Luc Buée, ${ }^{\dagger}$ Alain Boom, ${ }^{*}$ Karelle Leroy, ${ }^{*}$ Kunie Ando, ${ }^{*}$ and Jean-Pierre Brion*
}

From the Laboratory of Histology, Neuroanatomy and Neuropathology, * Faculty of Medicine, Université Libre de Bruxelles, ULB Neuroscience Institute, Brussels, Belgium; and INSERM, U837, ${ }^{\dagger}$ Université de Lille 2, Lille, France

\author{
Accepted for publication \\ June 6, 2016. \\ Address correspondence to \\ Jean-Pierre Brion, M.D., \\ Ph.D., Laboratory of Histol- \\ ogy, Neuroanatomy and \\ Neuropathology, Université \\ Libre de Bruxelles, School of \\ Medicine, 808, route de Len- \\ nik, Bldg GE, 1070 Brussels, \\ Belgium. E-mail: jpbrion@ \\ ulb.ac.be.
}

\begin{abstract}
In Alzheimer disease, the development of tau pathology follows neuroanatomically connected pathways, suggesting that abnormal tau species might recruit normal tau by passage from cell to cell. Herein, we analyzed the effect of stereotaxic brain injection of human Alzheimer high-molecular-weight paired helical filaments (PHFs) in the dentate gyrus of wild-type and mutant tau THY-Tau22 mice. After 3 months of incubation, wild-type and THY-Tau22 mice developed an atrophy of the dentate gyrus and a tau pathology characterized by Gallyas and tau-positive grain-like inclusions into granule cells that extended in the hippocampal hilus and eventually away into the alveus, and the fimbria. Gallyaspositive neuropil threads and oligodendroglial coiled bodies were also observed. These tau inclusions were composed only of mouse tau, and were immunoreactive with antibodies to $4 R$ tau, phosphotau, misfolded tau, ubiquitin, and p62. Although local hyperphosphorylation of tau was increased in the dentate gyrus in THY-Tau22 mice, the development of neurofibrillary tangles made of mutant human tau was not accelerated in the hippocampus, indicating that wild-type human PHFs were inefficient in seeding tau aggregates made of G272V/P301S mutant human tau. Our results indicate thus that injection of human wild-type Alzheimer PHF seeded aggregation of wild-type murine tau into an argyrophilic 4R tau pathology, and constitutes an interesting model independent of expression of a mutant tau protein. (Am J Pathol 2016, 186: 2709-2722; http://dx.doi.org/10.1016/j.ajpath.2016.06.008)
\end{abstract}

Alzheimer disease (AD) is the most common form of dementia in aged population and is becoming a critical social issue in our aging society. ${ }^{1}$ AD has two key neuropathological lesions: amyloid plaques and neurofibrillary tangles (NFTs). Amyloid plaques are made of extracellular deposits of amyloid $B$ peptides surrounded by dystrophic neurites and inflammatory cells. NFTs are composed of paired helical filaments (PHFs) constituted of hyperphosphorylated and misfolded tau proteins. ${ }^{2-4}$ Both amyloid and tau pathologies seem to contribute to neuronal dysfunction: NFTs, however, strongly correlate with cognitive deficits and are now considered as a valid therapeutic target. ${ }^{5}$ Tau-related neurodegenerative disorders are referred as tauopathies, including AD, Pick disease, familial frontotemporal dementia and parkinsonism linked to chromosome 17, progressive supranuclear palsy, corticobasal degeneration, argyrophilic grain disease, and

Supported by the Belgian Fonds de la Recherche Scientifique Médicale grant T.0023.15 (J.-P.B.), a Fund Aline (King Baudoin Foundation) grant (J.-P.B.), a Foundation for Alzheimer Research (FRA/SAO) grant (J.-P.B.), and a Fund Génicot grant (J.-P.B.). E.A. is a research fellow of Diane program (Walloon region) (816856) and K.A. is a research fellow of the Belgian Fonds National de la Recherche Scientifique. Part of the study was performed in the frame of the Interuniversity Attraction Poles program (P7/16) of the Belgian Federal Science Policy Office (J.-P.B.).

E.A. and S.H. contributed equally to this work.

K.A. and J.-P.B. contributed equally as senior authors.

Disclosures: JN-RF.5 mTau-5 was a gift from Marc Mercken, Johnson \& Johnson, Beerse, Belgium. 
others. ${ }^{2}$ According to a generally proposed scheme of successive modifications, tau proteins become initially hyperphosphorylated, followed by the formation of oligomers and finally of insoluble fibrillar aggregates assembled into abnormal PHFs. Abnormal PHF-tau molecular species at each of these steps might be responsible for toxicity and/ or spreading of tau pathology. Neuropathological studies indicate that NFT propagation in AD follows neuroanatomically connected pathways, first emerging in the locus coeruleus, ${ }^{6}$ then in the transentorhinal cortex, and spreading to limbic system and the neocortex. ${ }^{7,8}$ Indeed, tau pathology can be elicited or propagate in the brain by intracerebral injection of $\mathrm{AD}$ tissue, ${ }^{9-11}$ oligomeric tau, ${ }^{12}$ recombinant tau fibrils, ${ }^{13,14}$ local transgenic tau expression, ${ }^{15,16}$ and lentiviral-mediated tau expression. ${ }^{17}$ Tau spreading in vivo has been reported using brain homogenates from several tauopathies, including $\mathrm{AD}$, but the nature of nonmutant tau species responsible for spreading in complex fractions extracted from sporadic AD has not been fully determined. Many models showing efficient spreading in vivo rely on spreading of mutant tau aggregation induced by injection of mutant tau recombinant fibrils, often truncated, but their relevance for the understanding of tau pathology spreading in sporadic tauopathies, such as nonfamilial forms of $\mathrm{AD}$, needs futher investigations. To further investigate these issues, we analyzed the ability of native fractions containing PHF (made of high-molecularweight assembly of abnormal wild-type human PHF-tau) extracted from sporadic $\mathrm{AD}$ brain to initiate tau seeding after stereotaxic intracerebral injection in wild-type mice and in a mutant tau mouse model developing a robust tau pathology (THY-Tau22). ${ }^{18} \mathrm{We}$ observed that native AD PHF-tau seeded a $4 \mathrm{R}$ tau pathology in wild-type mice and in mutant tau mice, but did not accelerate the formation of Gallyas-positive tau aggregates made of overexpressed human mutant tau in the latter, suggesting differences in tau conformation between wild-type and mutant tau that refrain cross-seeding between them.

\section{Materials and Methods}

\section{Human Brain Tissue}

Human brain tissue samples were taken at autopsy from a nondemented control subject (81-year-old, male, post mortem delay of 16.5 hours) or from a demented patient (65year-old, male, post mortem delay of 30 hours) clinically diagnosed as having $\mathrm{AD}$ and were fixed with formalin $10 \%$ and embedded in paraffin or were kept at $-80^{\circ} \mathrm{C}$. The neuropathological examination confirmed the presence of numerous NFTs and amyloid plaques in this AD case (NFT Braak stage VI, Thal 5) but not in the control case (Braak stage 0 , Thal 0 ). This study on postmortem brain tissue was performed in compliance with and following approval of the Ethical Committee of the Medical School of the Free University of Brussels.

\section{Preparation of Human Sarkosyl-Insoluble}

\section{PHF-Tau Fraction}

Sarkosyl fractionation of human brain tissue was performed as previously described. ${ }^{19-21}$ A total of $0.5 \mathrm{~g}$ of frozen frontal cortex from control and AD cases was homogenized in 10 volumes of ice-cold PHF-extraction buffer $(10 \mathrm{mmol} / \mathrm{L}$ Tris-HCl, pH 7.4, $0.8 \mathrm{~mol} / \mathrm{L} \mathrm{NaCl}, 1$ $\mathrm{mmol} / \mathrm{L}$ EDTA, and $10 \%$ sucrose). The homogenate was centrifuged at $15,000 \times g$ for 20 minutes at $4^{\circ} \mathrm{C}$. The pellet was rehomogenized with PHF-extraction buffer and recentrifuged. The first and second supernatants were pooled, and N-lauroylsarcosine sodium salt (L-5125; Sigma-Aldrich) was added to reach a final concentration of $1 \%(\mathrm{w} / \mathrm{v})$. The lysate was incubated at room temperature for 30 minutes with a mild agitation followed by an ultracentrifugation at $180,000 \times g$ for 30 minutes at $4^{\circ} \mathrm{C}$. The Sarkosyl soluble supernatant was removed, and the Sarkosyl-insoluble pellet was briefly rinsed and resuspended in $0.25 \mathrm{~mL}$ of $50 \mathrm{mmol} / \mathrm{L}$ Tris- $\mathrm{HCl}(\mathrm{pH} 7.4)$ by vigorous pipetting. The protein concentration was determined by Bradford protein assay (Bio-Rad, Hercules, CA) and adjusted for $0.5 \mathrm{mg} / \mathrm{mL}$. This Sarkosyl-insoluble PHFtau fraction was aliquoted and kept at $-80^{\circ} \mathrm{C}$.

\section{Negative Staining of Tau Filaments in Electron Microscopy}

The pellet containing the Sarkosyl-insoluble material was resuspended in $50 \mathrm{mmol} / \mathrm{L}$ Tris/ $\mathrm{HCl}(\mathrm{pH} \mathrm{7.5)}$. This material was adsorbed on formvar-carbon coated EM grids and negatively stained with potassium phosphotungstate as reported, ${ }^{22}$ before observation with a Zeiss EM 809 at $80 \mathrm{kV}$.

\section{Cell Cultures}

CHO cells were grown in HAM F12 medium supplemented with $10 \%$ fetal bovine serum, $100 \mathrm{IU}$ penicillin, and $100 \mu \mathrm{g} /$ $\mathrm{mL}$ streptomycin and incubated at $37^{\circ} \mathrm{C}$ with a $95 \%$ air $/ 5 \%$ $\mathrm{CO}_{2}$ mixture. The $102 \mathrm{C} 5$ clonal $\mathrm{CHO}$ cell line expresses the $2 \mathrm{~N} 3 \mathrm{R}$ tau isoform conjugated to enhanced green fluorescent protein. $^{23}$

\section{Ultrastructural Analysis in Electron Microscopy}

Cultured CHO cells were treated for 24 hours with Sarkosyl-insoluble PHF at a concentration of $10 \mu \mathrm{g} / \mathrm{mL}$. The cells were fixed with $4 \%$ (v/v) glutaraldehyde in $0.1 \mathrm{~mol} / \mathrm{L}$ phosphate buffer at $\mathrm{pH} 7.4$, as previously described. ${ }^{24}$ After washing in Millonig's buffer with $0.5 \%$ $(\mathrm{w} / \mathrm{v})$ sucrose for 24 hours, cells were postfixed in $2 \%$ (w/v) $\mathrm{OsO}_{4}$ for 30 minutes, dehydrated, and embedded in Epon. Semithin sections were stained with toluidine blue. Ultrathin sections were counterstained with lead citrate and uranyl acetate and observed with a Zeiss EM 809 at $80 \mathrm{kV}$. 


\section{Denaturing and Nondenaturing PAGE}

Proteins in Sarkosyl-insoluble materials were mixed with either Laemmli buffer or native sample buffer (SDS and $\beta$-mercaptoethanol were omitted from Laemmli). For denaturating condition, samples were heated in Laemmli buffer at $100^{\circ} \mathrm{C}$ for 5 minutes and applied to $10 \%$ Tris-glycine SDSPAGE using mini PROTEAN III system, according to the manufacturer's instructions (BioRad). For native PAGE, samples were applied with or without heating at $100^{\circ} \mathrm{C}$ for 5 minutes to $8 \%$ native gel $[273 \mathrm{mmol} / \mathrm{L}$ Tris- $\mathrm{HCl}, \mathrm{pH} 8.8,8 \%$ acrylamide/bis-acrylamide (19:1), $0.1 \%$ ammonium persulfate, $0.1 \%$ TEMED] in tris-glycine running buffer (without SDS), and were transferred to nitrocellulose membrane (sc-3718, SCBT) using a liquid transfer system (BioRad, Hercules, CA). For Western blotting, the nitrocellulose membranes were blocked with $10 \% \mathrm{w} / \mathrm{v}$ semifat dry milk in tris-buffered saline $(0.01 \mathrm{~mol} / \mathrm{L}$ Tris, $0.15 \mathrm{~mol} / \mathrm{L} \mathrm{NaCl}, \mathrm{pH}$ 7.4) and incubated with primary antibody for overnight. After several rinses, the membranes were incubated with antirabbit (7074; Cell Signaling, Leiden, the Netherlands) or anti-mouse (A6782; Sigma, St. Louis, MO) secondary antibodies conjugated with horseradish peroxidase and developed with the ECL system (Pico; ThermoFisher Scientific, Gent, Belgium). The chemiluminescent signal was captured using a Fusion SOLO 4S system (Vilber Lourmat) equipped with a DARQ-7 camera.

\section{Wild-Type and THY-Tau22 Mouse Line}

THY-Tau22 mice express a 1N4R human tau isoform mutated at positions G272V and P301S, under control of a Thy1.2 promoter, and display tau pathology in absence of motor dysfunction. ${ }^{18}$ Gallyas-positive NFTs appear in the cortex and the hippocampus at 6 months of age in THYTau22 mice. ${ }^{18}$ All of the THY-Tau22 mice used in this study were heterozygous and maintained on a C57/BL6 background. A total of 38 female mice were used in this study: 19 wild-type C57/BL6 and 19 THY-Tau22 mice were injected with Sarkosyl-insoluble materials from control nondemented brain (wild-type, $n=8$; THY-Tau22, $n=6$ ) or from AD brain (wild-type, $n=8$; THY-Tau22, $n=13$ ) and sacrificed 3 months after injection; three wild-type mice were injected with Sarkosyl-insoluble material from AD and sacrificed 6 months after injection. All studies on animals were performed in compliance with and after approval of the ethical committee for the care and use of laboratory animals of the Medical School of the Free University of Brussels.

\section{Stereotaxic Brain Injection}

Three-month-old wild-type and THY-Tau22 mice were deeply anesthetized with a solution of xylazine $(5 \% \mathrm{v} / \mathrm{v})$ (Rompun, Bayer) and ketamine hydrochloride (10\% v/v) (Nimatek) in physiological saline by i.p. injection $(100 \mu \mathrm{L} /$ $10 \mathrm{~g}$ of body weight, final dose, $10 \mathrm{mg} / \mathrm{kg}$ xylazine, and 100 $\mathrm{mg} / \mathrm{kg}$ ketamine) and placed in a stereotaxic apparatus (Kopf Instruments, Tujunga, CA). Unilateral stereotaxic injections (left hemisphere) were performed in the hippocampus at the level of the dentate gyrus (rostrocaudal, -2.1 $\mathrm{mm}$; lateral, $1.5 \mathrm{~mm}$; depth, $-2.0 \mathrm{~mm}$ ). One microgram of Sarkosyl-insoluble material was injected in a volume of 2 $\mu \mathrm{L}$ at the concentration of $0.5 \mu \mathrm{g} / \mu \mathrm{L}$ at a speed of $0.2 \mu \mathrm{L} /$ minute with a pump (kdScientific, Holliston, MA), using a $200-\mu \mathrm{m}$ diameter needle (ThermoFisher Scientific). The needle was gently removed 5 minutes after injection.

\section{Motor Testing}

Motor deficits in wild-type and THY-Tau22 mice were evaluated by testing them on a rotarod apparatus (Ugo Basile), as described previously. ${ }^{25}$ Briefly, animals were first submitted to training sessions (three trials per day during 3 consecutive days before injection) during which they were placed on the rod rotating with a progressive acceleration from 4 to $40 \mathrm{rpm}$. Animals were individually separated the day before the test and evaluated using the same experimental setting throughout 300 seconds. The latency to fall off the rotarod was recorded. Animals staying $>300$ seconds were removed from the rotarod, and their latency fall recorded as 300 seconds. Mice were tested 1, 2, and 3 months after injection.

\section{Behavioral Testing}

Treated and untreated mice were tested in the Y-maze for spontaneous alternation, as described previously. ${ }^{26}$ The number of total entries in the arms, the numbers of alternations, and the total run distance were calculated. The percentage of spontaneous alternations was expressed as the number of alternations divided by the total number of arms -2 . Repeated entries in the arms were accepted, resulting in a chance performance level of $22 \%$ alternation. ${ }^{27}$ Mice were tested before injection and then 1,2, and 3 months after injection.

\section{Antibodies}

The B19 antibody is a rabbit polyclonal antibody raised to adult bovine tau proteins. This antibody reacts with all known adult and fetal tau isoforms in bovine, rat, mouse, and human nervous tissue in a phosphorylation-independent manner. ${ }^{20}$

The BR21 rabbit polyclonal antibody is specific for human tau. ${ }^{28}$ Antibody JN-RF.5 mTau-5 (generous gift from Marc Mercken, Johnson \& Johnson, Beerse, Belgium) reacts only with murine tau. ${ }^{29}$ The mouse monoclonal antibodies to ubiquitin (MAB1510) and to caspase cleaved tau (Asp421) (MAB5430) were purchased from Millipore (Merckgroup, Overijse, Belgium). The AT8, AT180, AT270, and AT100 mouse monoclonal antibodies (purchased from Innogenetics, Ghent, Belgium) are specific for tau phosphorylated at Ser202 and Thr205 (AT8), ${ }^{30}$ at 
Thr231 (AT180), and a specific PHF-tau epitope involving phosphorylation at Thr212 and Ser214 (AT100). ${ }^{31}$ The mouse monoclonal antibodies PHF1 (kindly provided by Dr. Peter Davies, New York, NY) and AP422 (kindly provided by Drs. Masato Hasegawa and Michael Goedert, Cambridge, UK) are specific for tau phosphorylated at Ser396/404 and Ser422, respectively. ${ }^{32,33}$ The tau monoclonal antibody MC1 (also provided by Dr. Davies) recognizes a conformational epitope requiring both an $\mathrm{N}$-terminal fragment and a C-terminal fragment. ${ }^{34}$ The polyclonal rabbit antibodies to neurofilament M (NA1216) and phosphorylated neurofilament $\mathrm{H}$ (NA 1211) were from Affiniti (Exeter, UK). Anti-MAP2 B9 antibody was produced in rabbit. ${ }^{35}$ Rabbit polyclonal anti-oligomer tau T22 antibody was a generous gift from Dr. Rakez Kayed (University of Texas, Austin, TX). ${ }^{36}$ Rabbit polyclonal anti-p62/SQSTM-1 antibody (NBP1-48320) was purchased from Novusbio (Littleton, $\mathrm{CO}$ ). Mouse monoclonal anti-Aß 6E10 antibody was purchased from Covance (Princeton, NJ).

\section{Histological Staining and Immunocytochemistry}

Mice were sacrificed by cervical dislocation and brains were fixed in $10 \%(\mathrm{v} / \mathrm{v})$ formalin for 24 hours before embedding in paraffin. Tissue sections ( $7 \mu \mathrm{m}$ thick) were stained with the Gallyas silver-staining method to identify neurofibrillary tangles. They were examined with a Zeiss Axioplan microscope, and digital images acquired using an Axiocam HRc camera. The immunohistochemical labeling was performed using the $\mathrm{ABC}$ method. Briefly, tissue sections were treated with hydrogen peroxide to inhibit endogenous peroxidase and incubated with the blocking solution [10\% (v/v) normal horse serum in tris-buffered saline]. After an overnight incubation with the diluted primary antibody, the sections were sequentially incubated with either horse antimouse or goat anti-rabbit antibodies conjugated to biotin (Vector Laboratories) followed by the $\mathrm{ABC}$ complex (Vector Laboratories). The peroxidase activity was developed using diaminobenzidine as chromogen. Double immunolabeling was performed using fluorescent markers. The first antibody was detected using an anti-rabbit $\operatorname{IgG}$ conjugated to horseradish peroxidase (7074; Cell Signaling) and revealed with tyramide-fluorescein isothiocyanate (Perkin Elmer, Zaventem, Belgium), the second antibody detected using an anti-mouse antibody conjugated to biotin, followed by streptavidin conjugated to Alexa 594 (Molecular Probes, Gent, Belgium). Double immunolabeling was followed by nuclear DAPI staining.

\section{Analysis of Hippocampal Area Subfields and Density of AT8 and Gallyas-Positive NFTs in the Hippocampus}

The cross-sectional surface area of several subfields of the hippocampus on the injected and the noninjected sides was estimated using a Cavalieri estimator probe implemented into stereology software (Stereoinvestigator version 8;
MicroBrightField, Magdebourg, Germany). ${ }^{28}$ The measured areas included the granule cell layer, the molecular layer of the dentate gyrus, the hippocampal hilus (CA4 sector), and the CA1-CA3 sectors of the Ammon's horm (stratum pyramidale, stratum radiatum, and stratum oriens). These measurements were performed on sections at levels of the injection site. The absolute number of Gallyas- and AT8positive cells were counted in the granule cell layer and in the Ammons' horn and their density was calculated according to the measured surface in these areas.

\section{Statistical Analysis}

Statistical analysis was performed using the Prism program version 5.0 (Graphpad Software, San Diego, CA). Statistical comparisons were performed using unpaired two-tailed Student's $t$-tests or Mann-Whitney $U$ tests as noted in figure legends. Values of $P<0.05$ were considered significant.

\section{Results}

Native Sarkosyl-Insoluble PHF-Tau Fraction from AD Brain Contains PHF and Only High-Molecular-Weight Tau Species

We analyzed the biochemical and morphological characteristics of the native PHF-tau in the Sarkosyl-insoluble fraction extracted from $\mathrm{AD}$ and control brains and used for injection. As described previously using denaturing SDSPAGE ${ }^{20}$ PHF1-positive hyperphosphorylated tau was present in Sarkosyl-insoluble fraction from AD brain as three major species of 57 to $69 \mathrm{kDa}$ but was absent from control case (Figure 1A). Sarkosyl-insoluble fraction from AD brain did not contain monomeric or oligomeric tau running into the gel when analyzed in nondenaturing, native gel in the absence of SDS and $\beta$-mercaptoethanol (Figure 1B). Highmolecular-weight tau aggregates $(>242 \mathrm{kDa})$ and lowmolecular-weight oligomeric tau $(<242 \mathrm{kDa})$ could be detected by incubating Sarkosyl-insoluble PHF-tau fraction in Laemmli buffer containing SDS and $\beta$-mercaptoethanol at room temperature (Figure 1B). Further incubation in Laemmli buffer at $100^{\circ} \mathrm{C}$ increased the levels of detectable oligomeric tau and generated even lower-molecular-weight tau species (up to $140 \mathrm{kDa}$ ) (Figure 1B), indicating that native Sarkosyl-insoluble fraction mainly contains highmolecular-weight tau that can be partially solubilized by SDS and $\beta$-mercaptoethanol. The presence of fibrillar tau in the form of PHF in native Sarkosyl-insoluble fraction from $\mathrm{AD}$ brain was confirmed by negative staining in electron microscopy (Figure 1C). We also tested for the presence of $A B$ in the Sarkosyl-insoluble fraction by Western blotting with the $6 \mathrm{E} 10$ antibody: monomeric or oligomeric $A B$ was not detected in this fraction used for stereotaxic injection (data not shown). 


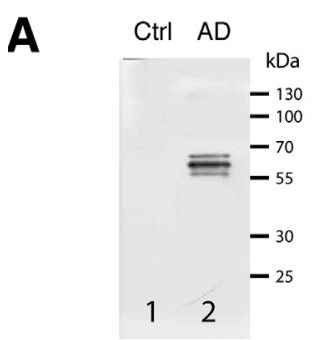

$\mathbf{F}$

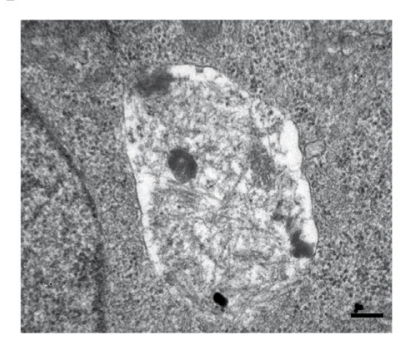

B

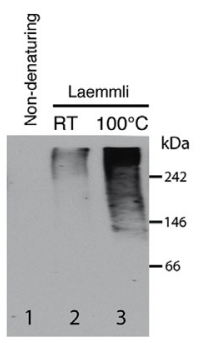

G

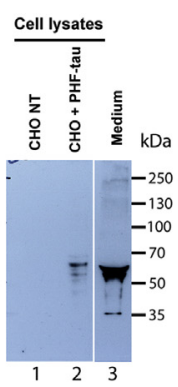

C

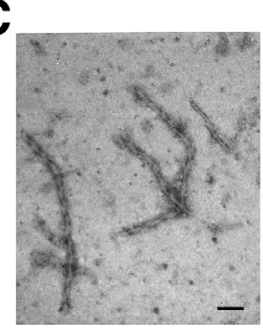

H

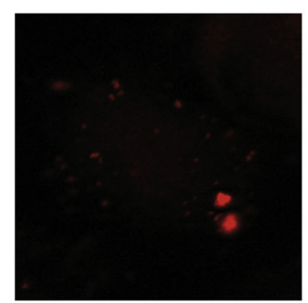

D

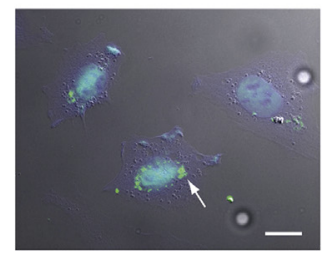

I

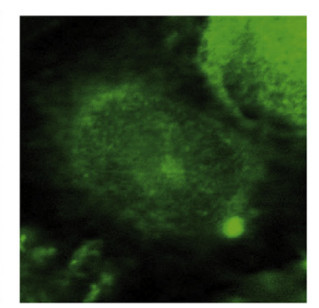

E

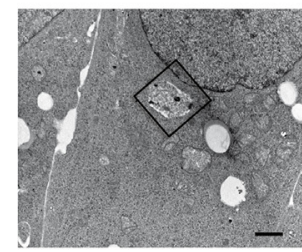

J

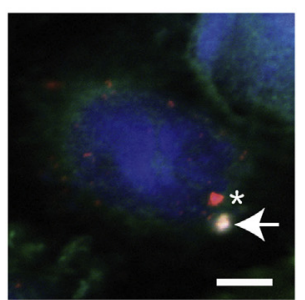

Figure 1 A-C: Sarkosyl-insoluble paired helical filament (PHF)-tau from Alzheimer disease (AD) brain is constituted only of high-molecular-weight tau species. A: Western blot analysis with the anti-phosphotau PHF1 antibody of Sarkosyl-insoluble fraction (frontal cortex) from a control subject (Ctrl) and from an $A D$ patient (AD) after denaturing SDS-PAGE. Absence of insoluble tau species in the control sample (lane 1). Three PHF-tau species of 57 to 69 kDa are detected in the AD sample (lane 2). B: Western blot with the anti-phosphotau PHF1 antibody. After nondenaturing PAGE, no oligomeric tau species are running into the gel (lane 1). Incubation of the Sarkosyl fraction in Laemmli buffer with SDS and $\beta$-mercaptoethanol (BME) at room temperature (RT) generates oligomeric tau species $>242 \mathrm{kDa}$ (lane 2). Incubation in Laemmli buffer with SDS and BME at $100^{\circ} \mathrm{C}$ increases the level of lower-molecular-weight oligomeric tau species running into the gel (lane 3). C: Transmission electron microscopy (TEM) analysis by negative staining. The Sarkosyl fraction of the AD patient contains numerous PHFs. D-G: Internalization of human AD PHF-tau in cultured CHO cells. D: CHO cells treated for 24 hours with PHF-tau. Immunofluorescence labeling with the B19 anti-tau antibody (green) combined with Nomarski interference contrast. Tau-positive intracytoplasmic grains are often observed in a perinuclear position (arrow). DAPI counterstaining. E and F: TEM analysis of CHO cells treated for 24 hours with Sarkosyl-insoluble PHF-tau. Short fibrils are present in an intracytoplasmic membrane-limited phagosome structure (boxed area in $\mathbf{E}$ is shown at higher magnification in $\mathbf{F}$ ) adjacent to the nucleus. G: Western blot analysis with the anti-phosphotau PHF1 antibody on the lysates of untreated cells (CHO NT; lane 1), lysates of cells treated for 24 hours with PHF-tau (lane 2, CHO + PHF), and of the culture medium of treated cells (lane 3). Tau-positive species are detected in the lysates of treated cells. H-J: Human AD PHF-tau seeds endogenous tau in cultured cells. Double immunolabeling of cultured clonal CHO cells stably expressing 2N3R tau-enhanced green fluorescent protein (EGFP; clone 102C5) treated for 24 hours with PHF-tau added in culture medium. H: Anti-phosphotau PHF1 (red). I: Anti-GFP (green). J: Merging of three channels (with DAPI nuclear counterstaining). Some of the intracytoplasmic inclusions are immunoreactive for both PHF1 and GFP (arrow) and some only for PHF1 (asterisk). Scale bars: $100 \mathrm{~nm}$ (C); $25 \mu \mathrm{m}$ (D and $\mathbf{H}-\mathbf{J}) ; 1 \mu \mathrm{m}(\mathbf{E}) ; 200 \mathrm{~nm}(\mathbf{F})$.

\section{Sarkosyl-Insoluble PHF-Tau Is Internalized into Cultured Cells without Any Transfection Agent}

We first wondered whether Sarkosyl-insoluble PHF-tau from human $\mathrm{AD}$ brains could be internalized into cells in vitro without adding any transfection agent, as in our stereotaxic injection protocol. Sarkosyl-insoluble PHFtau was added to the culture medium of $\mathrm{CHO}$ cells, which do not express tau proteins, at a concentration of $10 \mu \mathrm{g} /$ $\mathrm{mL}$ for 24 hours. The internalization of Sarkosylinsoluble PHF-tau was confirmed by immunolabeling of fixed and permeabilized cells using the anti-tau B19 antibody that labeled granular intracytoplasmic inclusions (Figure 1D). These intracytoplasmic inclusions often showed a perinuclear localization resembling aggresomes, as reported in a previous study. ${ }^{37}$ Western blotting of $\mathrm{CHO}$ cell lysate with the anti-phosphotau PHF1 antibody also detected PHF-tau species only in treated cells (Figure 1G). By electron microscopy, short PHFs in vesicular structures, most probably corresponding to phagosomes, were identified in CHO cells (Figure 1, E and F). These tau-positive intracellular vesicles were absent when
CHO cells were incubated with Sarkosyl-insoluble fraction from a control case (data not shown). These data provide evidence that Sarkosyl-insoluble PHF-tau can be internalized into cells without any transfection agents. We also incubated in the same conditions $102 \mathrm{C} 5$ cells stably expressing $2 \mathrm{~N} 3 \mathrm{R}$ tau-enhanced green fluorescent protein, and double labeled them with the phosphotau antibody PHF1 and the anti-GFP antibody (Figure 1, H-J). Many cells contained inclusions positive only for PHF1 (corresponding to PHF-tau inclusions) (Figure $1 \mathrm{H}$ ), but also inclusions positive for both PHF1 and GFP (Figure 1J), indicating that endogenous tau-enhanced green fluorescent protein colocalized with internalized Sarkosylinsoluble PHF-tau.

\section{Injected Human PHF-Tau Is Not Detected in Mouse Brains after 3 Months}

We then performed stereotaxic injection of Sarkosylinsoluble PHF-tau in the dentate gyrus to evaluate the ability of human Sarkosyl-insoluble PHF-tau to induce AD-like tau pathology in wild-type mice or to accelerate 

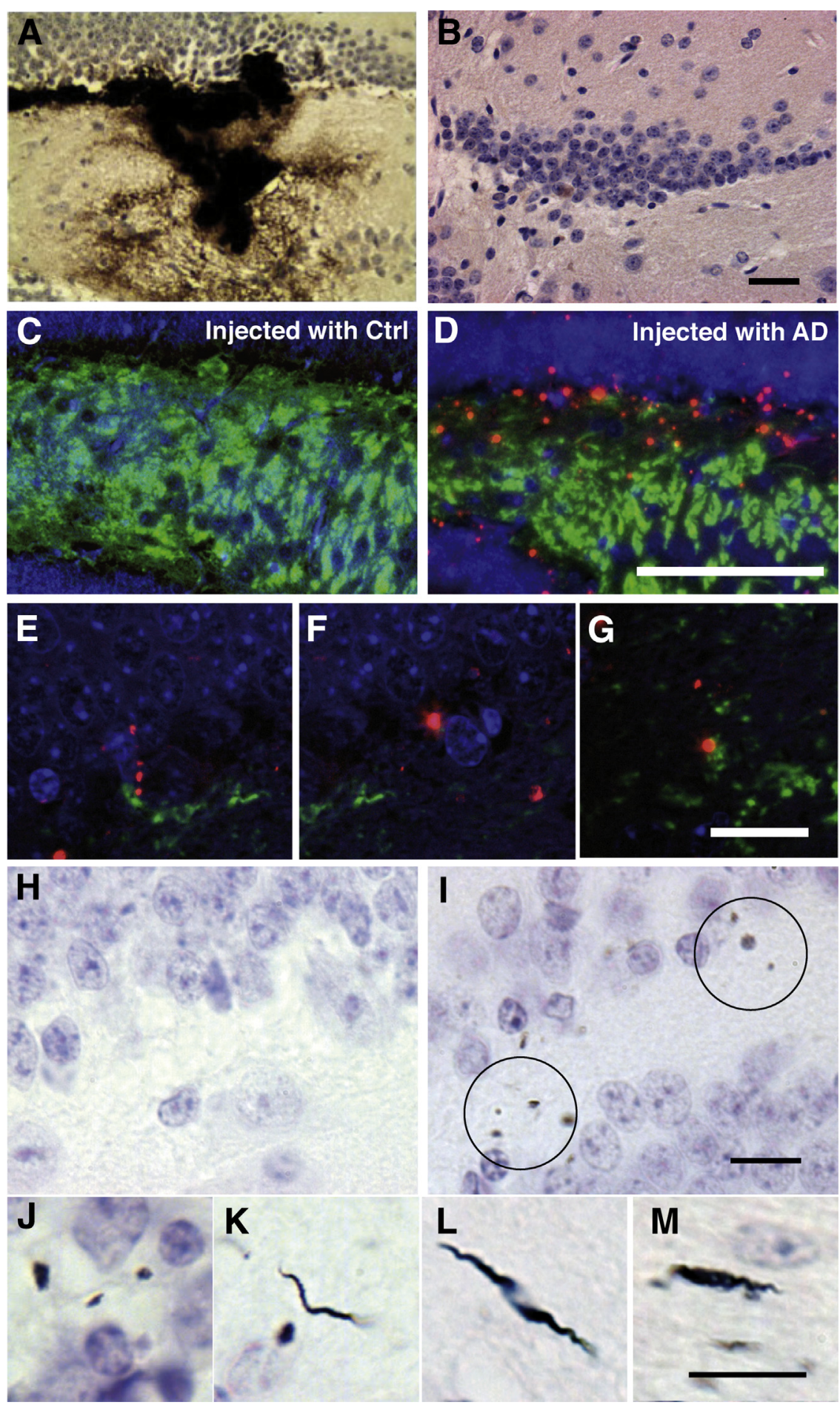

Figure 2 A-G: Human Alzheimer disease (AD) paired helical filament (PHF) induces formation of phosphotau-positive grains into wild-type mice. $\mathbf{A}$ and B: Immunolabeling with the anti-human tau BR21 antibody of the hippocampus (dentate gyrus) 24 hours (A) or 3 months (B) after injection in wildtype mouse injected with Sarkosyl-insoluble tau from $A D$ case. Human tau-positive material is detected 24 hours after injection but not anymore after 3 months. Hematoxylin counterstaining. C-G: Double-immunofluorescence labeling with antibodies to neurofilament (NF)-M (green) and to phosphotau (AT8) (red) in wild-type mice injected with Sarkosyl-insoluble fraction from control case (C) and with Sarkosyl-insoluble PHF-tau from AD case (D-G). Axonal Mossy fibers are strongly NF-M positive. Numerous phosphotau-positive granular structures are detected in the granule cell layer and in the hippocampal hilus after injection of Sarkosylinsoluble PHF-tau from AD case (D) but not after injection of Sarkosyl-insoluble fraction from control case (Ctrl; C). E-G: Phosphotau-positive grains are closely adjacent to granule cell nuclei $(\mathbf{E}$ and $\mathbf{F})$ or partially overlap with the axonal NF-M labeling (G). DAPI nuclear counterstaining (blue). H-M: Human AD PHF induces formation of argyrophilic grains into wild-type mice. Gallyas silver staining of the hippocampus in wild-type mouse injected with Sarkosyl-insoluble fractions from a control subject (H) or an AD case (I-M). $\mathbf{H}$ and I: Dentate gyrus. Gallyas-positive granular inclusions are detected in the granule cell layer and in the hilus in mice injected with Sarkosyl-insoluble fraction from $A D$ case (circles in I) but not in mice injected with Sarkosyl-insoluble fraction from a control subject (H). J-M: Gallyas-positive inclusions appear as granules $(\mathbf{J})$, neuropil threads $(\mathbf{K})$, coiled bodies (L), or small neurofibrillary tangles (M). Hematoxylin counterstaining. Scale bars: $25 \mu \mathrm{m}(\mathbf{A}, \mathbf{B}$, and $\mathbf{E}-\mathbf{G}) ; 100 \mu \mathrm{m}$ (C and $\mathbf{D}) ; 12.5 \mu \mathrm{m}(\mathbf{H}-\mathbf{M})$.
NFT formation in the Thy-Tau22 mice. ${ }^{18}$ Twenty-four hours after stereotaxic injection in wild-type mice, the injected Sarkosyl-insoluble fraction from AD brain, but not from control brain, was immunolabeled with the antihuman tau BR21 antibody (Figure 2A). After 3 months of incubation, this injected human PHF-tau was not detected anymore with the anti-human tau BR21 antibody (Figure 2B and Figure 3A).

\section{Human PHF Injection Leads to Appearance of Phosphotau-Positive Inclusions in Wild-Type Mice}

Three months after stereotaxic injection, wild-type and Thy-Tau 22 mice were analyzed for the presence of tau pathology by immunohistochemistry. In wild-type mice injected with AD Sarkosyl-insoluble PHF-tau, numerous small granular or ovoid inclusions (with diameters 


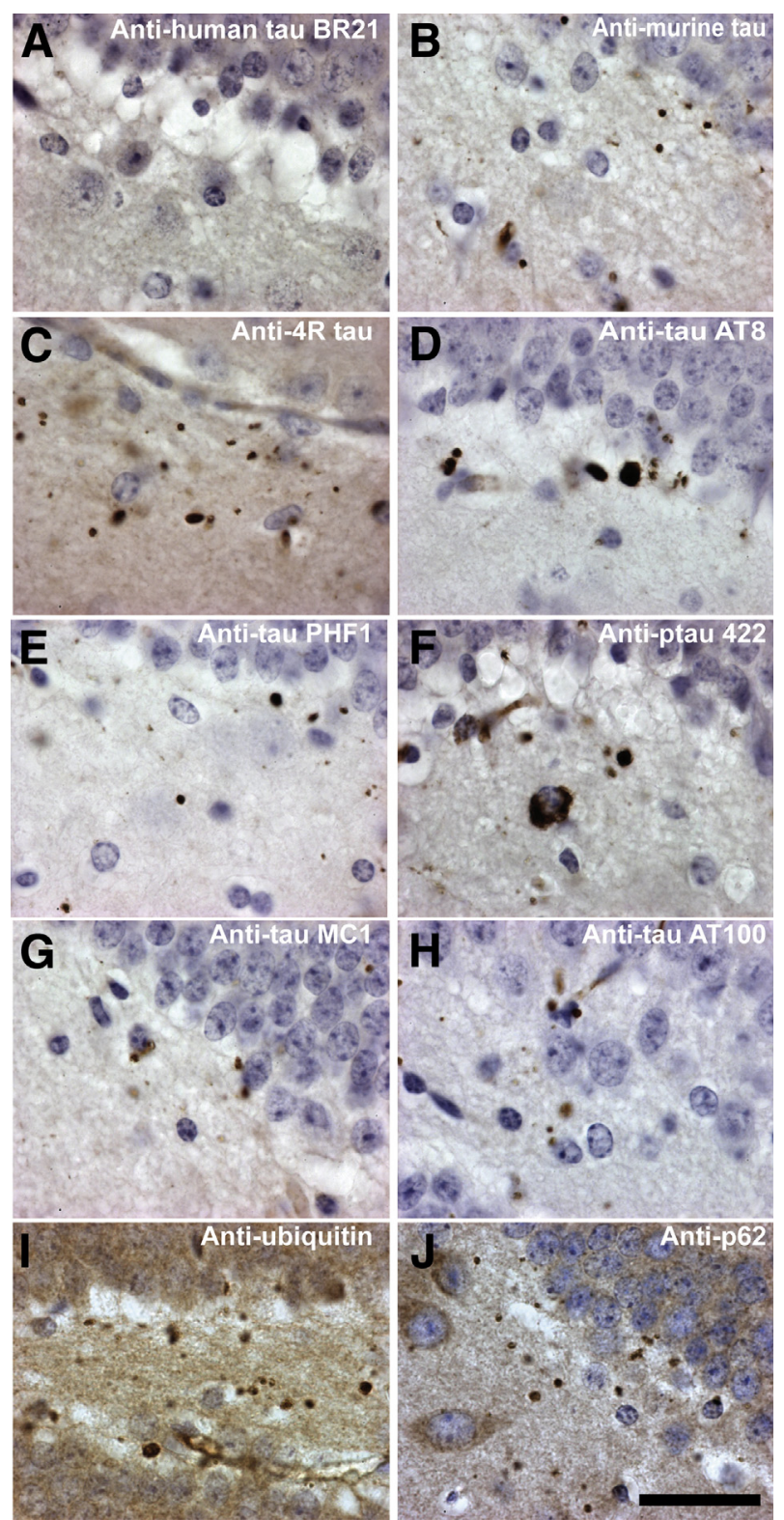

Figure 3 Paired helical filament (PHF)-induced tau inclusions have argyrophilic grain disease (AgD)-like 4R tau pathology. A-H: Phosphotaupositive grains contain abnormally phosphorylated, conformationally altered, and ubiquitinated murine tau. Immunolabeling of the dentate gyrus and its hilus in wild-type mice 3 months after injection with Sarkosylinsoluble PHF-tau from an Alzheimer disease (AD) case. A-C: Tau-positive grains are labeled with the antibodies to murine tau (B) and $4 R$ tau (C) but not by the BR21 antibody to human tau (A). D-F: Tau-positive grains are labeled with the phosphodependent tau antibodies AT8 (D), PHF1 (E), and pSer422 (F). G-H: Tau-positive grains are labeled with the abnormal conformation-dependent tau antibodies MC1 (G) and AT100 (H). I and J: Tau grains are ubiquitinated and p62 positive. Tau grains are labeled with antibodies to ubiquitin (I) and to p62 (J). Hematoxylin counterstaining. Scale bar $=25 \mu \mathrm{m}(\mathbf{A}-\mathbf{J})$.

ranging from 0.5 to $1 \mu \mathrm{m}$ or larger) were detected at the injection site with the anti-phosphotau AT8 (Figure 2D). These grain-like bodies were detected in the lower part of the molecular layer and in the granule cell layer of the dentate gyrus, in the subgranular zone and in the hilus of the Ammon's horn (Figure 2D). In the granule cell layer, these tau-positive grain-like bodies were often adjacent to nuclei of granule cells, suggesting a cytoplasmic localization (Figure 2, E and F). To analyze subcellular localization, neuron-specific dendritic marker anti-MAP2 (B9) antibody and pNFM antibodies were used for double staining. Double immunolabeling with the AT8 phosphotau antibody and the anti-MAP2 B9 antibody confirmed the occasional localization of AT8-positive grains into the pericarya of granule cells, but only their rare presence into MAP2-positive dendrites (data not shown). Double immunolabeling with the AT8 phosphotau antibody and the anti-pNFM showed in several mice that AT8-positive grains colocalized partially with neurofilament labeling (Figure $2 \mathrm{G}$ ) or were aligned in rows along pNFM-positive axons in axonal tracts (ie, in the alveus and the fimbria). Double-immunofluorescence labeling with AT8 and GFAP antibodies indicated that these tau-positive inclusions were rarely seen in astrocytes (data not shown). These tau-positive grains were never observed after injection of Sarkosyl-insoluble fraction from control subject (Figure 2C) and were not seen in the noninjected side.

\section{Human PHF Injection Leads to Appearance of Gallyas- Positive Inclusions in Wild-Type Mice}

These tau-positive inclusions were positive after Gallyas silver staining. The Gallyas-positive structures appeared with various morphologies: grains (Figure 2, I and J), neuropil threads (Figure 2K), coiled bodies (Figure 2L), and rare NFT-like small inclusions (Figure 2M). The argyrophilic grains were either loosely dispersed or arranged in rows, the latter apparently being located in nerve cell processes. These Gallyas-positive grains were absent in mice injected with Sarkosyl-insoluble fraction from control brain (Figure $2 \mathrm{H}$ ) or in the noninjected side.

Tau-Positive Inclusions Induced by Human Native PHFs Are Composed Only of Hyperphosphorylated and Conformationally Altered Murine Tau

To detail the molecular composition of these Gallyas- and tau-positive inclusions, immunolabeling was performed using various antibodies. These grains were not labeled by the anti-human tau BR21 antibody 3 months after injection (Figure 3A) but were labeled with the anti-murine tau mTau5 antibody (Figure 3B). Tau isoforms with three (3R) and four (4R) microtubule-binding repeats are present in human native PHF, but only 4R tau isoforms are expressed in adult mice. ${ }^{38}$ These grain-like inclusions were labeled with the anti-4R tau isoform RD4 antibody (Figure 3C), but not with the anti-3R tau isoform RD3 antibody (data not shown). They were also labeled by the phosphotau antibodies AT8 (Figure 3D), PHF1 (Figure 3E), AT180, AT270 (data not 

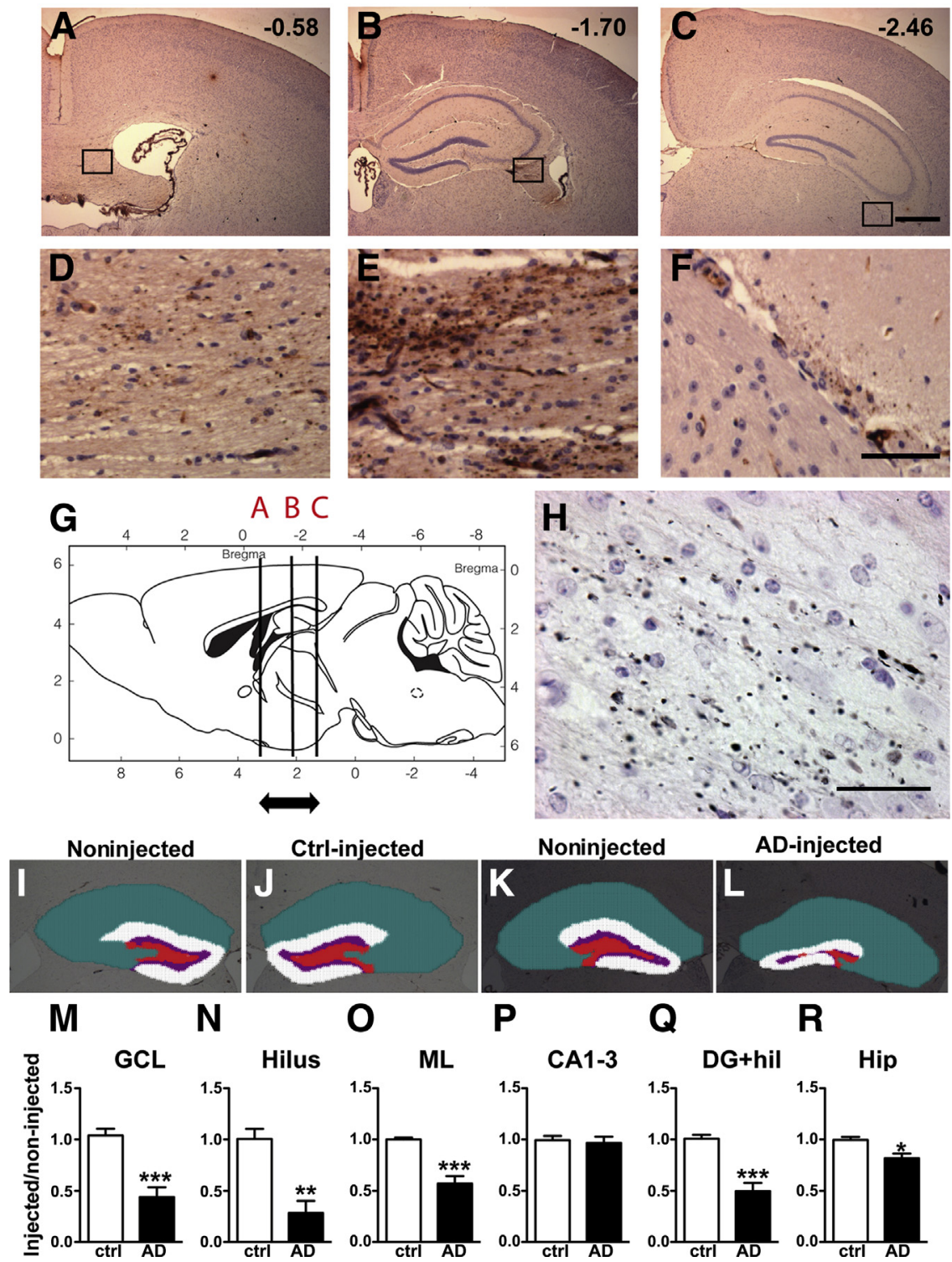

Hilus

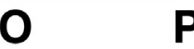

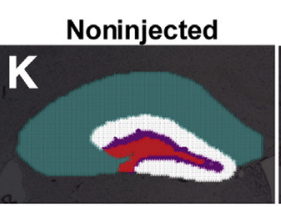
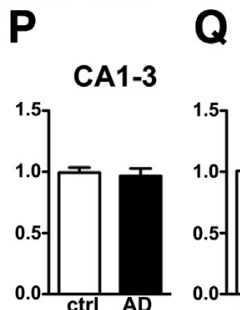

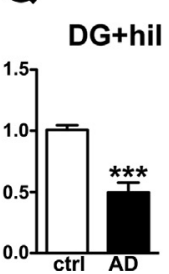

AD-injected

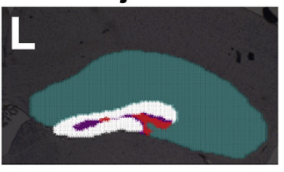

$\mathbf{R}$

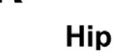

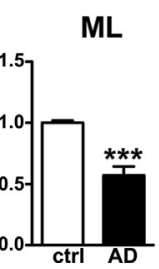

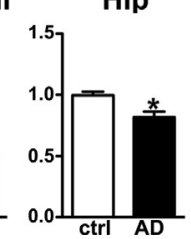

Figure 4 A-H: Rostrocaudal propagation of phosphotau-positive grains. Immunolabeling with the phosphotau AT8 antibody on brain coronal sections of a wild-type mouse injected with Sarkosyl-insoluble paired helical filament (PHF)-tau from an Alzheimer disease (AD) case. A-C: Coronal section at the level of the stereotaxic injection (B), and at the extreme rostral (A) and caudal (C) levels where phosphotau-positive grains were observed. Numbers refer to the position of the coronal section relative to the bregma (Paxinos Atlas). D-F: Higher magnification of the boxed areas shown in the coronal sections in $\mathbf{A}-\mathbf{C}$, respectively. AT8-positive grains are detected in axonal tracts in the corpus callosum, the alveus, and the fimbria. G: Sagittal mouse brain schematic section indicating the level of the three coronal sections shown in $\mathbf{A}-\mathbf{C}$. The rostrocaudal expansion of tau pathology encompasses a 2-mm wide region. H: Gallyas-stained section showing Gallyas-positive grains in the fimbria, with some single file disposition. Hematoxylin counterstaining. I-R: Human PHF injection induces a significant atrophy of the dentate gyrus. I-L: Representative drawings of coronal sections of the hippocampus at the level of stereotaxic injections in wild-type mice injected with Sarkosylinsoluble fractions from a control case (I and $\mathbf{J}$ ) or Sarkosyl-insoluble tau from an $A D$ case ( $K$ and $\mathbf{L}$ ), showing the injected sides ( $\mathbf{J}$ and $\mathbf{L}$ ) and the contralateral noninjected sides ( $\mathbf{I}$ and $\mathbf{K}$ ). The color codes indicate the area covered by the granule cell layer (purple), the molecular layer of the dentate gyrus (white), the hippocampal hilus (red), and the CA1 to CA3 hippocampal sectors (stratum pyramidale, stratum oriens, and stratum radiatum; green). $\mathbf{M}-\mathbf{R}$ : The atrophy was measured by calculating the ratios of the surfaces of the injected side versus the noninjected side, after injection of sarkosyl-insoluble fraction from a control (Ctrl) or an $A D$ case. The ratio of surface area was calculated for the granule cell layer (GCL; $M$ ), the hippocampal hilus $(\mathbf{N})$, the molecular layer of the dentate gyrus $(\mathrm{ML} ; \mathbf{0})$, the $\mathrm{CA} 1$ to $\mathrm{CA} 3$ sector $(\mathrm{P})$, the dentate gyrus combined with the hilus (hil; $\mathbf{Q}$ ), and the whole hippocampus (R). These ratios are significantly decreased in the $\mathrm{GCL}$, the hilus, the molecular layer, the dentate gyrus (DG), and the hippocampus. ${ }^{*} P<0.05,{ }^{* *} P<0.01$, and ${ }^{* *} P<0.001$, by unpaired Student's $t$-test. Scale bars: $0.5 \mathrm{~mm}(\mathbf{A}-\mathbf{C})$; $50 \mu \mathrm{m}$ (D-F); $25 \mu \mathrm{m}$ (H). shown), and pSer422 (Figure 3F) and the conformationdependent anti-tau antibodies MC1 (Figure 3G), AT100 (Figure 3H), and Alz50 (data not shown). Grains were also labeled by the anti-ubiquitin antibody (Figure 3I) and the anti-p62 antibody (Figure 3J). They were, however, negative for anti-caspase cleaved tau Asp421 or anti-oligomeric tau T22 (data not shown). Such tau-positive grains were not observed in mice injected with Sarkosyl-insoluble fraction from a control case (Supplemental Figure S1). These data suggest that the Gallyas-positive grains were mainly composed of hyperphosphorylated and abnormally phosphorylated and of conformationally altered adult murine tau, but not of human AD PHF-tau.

\section{Expansion of Tau Pathology in Wild-Type Mice Injected with Human PHF}

We then analyzed the expansion of tau-positive grains in the wild-type mice injected with Sarkosyl-insoluble PHF-tau. Tau-positive grains were present at the injection site in the dentate gyrus (see above), but this tau pathology was also detected in the hilus of the Ammon's horn and was spreading to stratum oriens and stratum radiatum of Ammon's horn, the alveus, and the fimbria in the ipsilateral hemisphere of wildtype mice injected with Sarkosyl-insoluble fraction from AD brain. The rostrocaudal expansion of tau pathology was next analyzed on serial coronal sections (Figure 4, A-F). We 
observed that the expansion of tau pathology could be estimated up to $1.5 \mathrm{~mm}$ rostrally and $0.5 \mathrm{~mm}$ caudally from the injection site (Figure 4G). Tau-positive grains were identified in the alveus (Figure 4F) and in the fimbria (Figure 4H) in the injected hemisphere in many injected mice. Grains were also identified in the corpus callosum in some mice (Figure 4, A and D), but such a tau pathology was not identified in the contralateral hemisphere.

\section{Human PHF Injection Induces a Significant Atrophy of the Dentate Gyrus}

To assess if stereotaxic injection was associated with neuronal and process loss in the hipoccampus, we measured on coronal sections at the level of injection the area covered by the granule cell layer and the molecular layer of the dentate gyrus, by the CA4 sector (hippocampal hilus) and by the CA1 to CA3 sectors of the hippocampus in the injected and the noninjected hemispheres (Figure 4, I-L). We next calculated for each section the ratio of these measurements (injected versus noninjected sides), a ratio value of 1.0 being expected in absence of tissue atrophy. After injection of Sarkosyl-insoluble PHF-tau, but not after injection of control fractions, these ratios were significantly decreased in wild-type mice in the granule cell layer (Figure $4 \mathrm{M}$ ), in the molecular layer of the dentate gyrus (Figure 4O), in the hippocampal hilus (Figure 4N), in the whole dentate gyrus (Figure 4Q), and in the whole hippocampus (Figure 4R), but not in the CA1 to CA3 sectors (Figure 4P). In THY-Tau22 mice (data not shown), these ratios were also significantly decreased in the molecular layer of the dentate gyrus and in the whole dentate gyrus, and showed a nonsignificant decrease in the granule cell layer and in the hippocampal hilus. Thus, these results indicate that injection of human PHF induced a significant atrophy of the dentate gyrus in both wild-type and THYTau22 mice.

\section{Human PHF Injection in THY-Tau22 Induces Gallyas-}

Positive Grains Mainly Composed of Murine Tau without Significantly Accelerating Aggregation of Human Mutant Tau

Gallyas-positive grains were also identified in THY-Tau22 mice injected with Sarkosyl-insoluble PHF-tau in the injected side (Figure 5B) but not in the noninjected side (Figure 5A). These grain-like inclusions in THY-Tau 22 mice showed a similar pattern of tau immunoreactivities as in wild-type mice. Indeed, most of the grains induced by human PHF injection were phosphotau positive but most were not labeled by the BR21 antibody to human tau. These data indicate that the Gallyas-positive grains induced by human AD PHF were almost exclusively composed of endogenous murine tau but not of human double mutant tau in THY-Tau 22 mouse brains (Figure 5C). To evaluate the ability of injected human PHFtau to accelerate the seeding and spreading of tau pathology in THY-Tau22 mice, we next measured the density of AT8positive neurons and of Gallyas-positive neurons in the granule cell layer and the pyramidal layer of Ammon's horn in the mouse brains injected with control or AD PHF. The density of AT8-positive cells in the dentate gyrus was significantly increased in the injected side (Figure 5, E and F) in mice injected with PHF but not in mice injected with control fraction (Figure 5D). In the CA1 to CA3 pyramidal layer (Figure 5, G and H), the density of AT8-positive cells was not different between mice injected with Sarkosylinsoluble PHF-tau or control fraction (Figure 5I). No significant difference in the density of Gallyas-positive neurons was observed in the granular cell layer or in CA1 to CA3 region between mice injected with PHF or control fraction (data not shown).

\section{Absence of Deficit in Working Memory and of Motor Deficit 3 Months after PHF Injection}

Before injection and 1, 2, and 3 months after injection of Sarkosyl-insoluble fractions, we tested in injected mice working memory by $\mathrm{Y}$ maze test and motor function by rotarod test. There were no significant differences in the memory and motor performance among mice injected with Sarkosyl-insoluble fraction from control or from AD cases (data not shown).

\section{Discussion}

Seeding and propagation of tau pathology has been supported by studies in various in vitro and in vivo models using different sources of tau proteins. Recombinant mutant tau fibrils and $\mathrm{AD}$ brain homogenates induce tau pathology in transgenic mice, but induction of tau pathology in vivo using bona fide human PHF extracted from sporadic AD brain has not been fully analyzed. In this study, we focused on the ability of paired helical filaments made of high-molecular-weight wild-type human $\mathrm{AD}$ PHF-tau to induce tau pathology in wild-type mice and to foster tau pathology in a mutant tau transgenic mouse model.

We confirmed that injected material contained highmolecular-weight tau aggregates in the form of PHF, and not oligomeric or monomeric tau, as shown by nondenaturing PAGE and electron microscopy. Compared to recombinant tau fibrils, human native PHFs have added properties. PHF from $\mathrm{AD}$ brains contains the six human wild-type tau isoforms aggregated natively during the evolution of $\mathrm{AD}$. Also, these PHF-tau proteins exhibit all of the hyperphosphorylation and abnormal phosphorylation changes ${ }^{2,39}$ and other post-translational modifications identified in the human disease (acetylation, nitration, glycosylation, truncation). ${ }^{40}$ All or some of these tau modifications might play an essential role in tau internalization, seeding, and spreading. Human native PHF could be readily internalized in cultured 

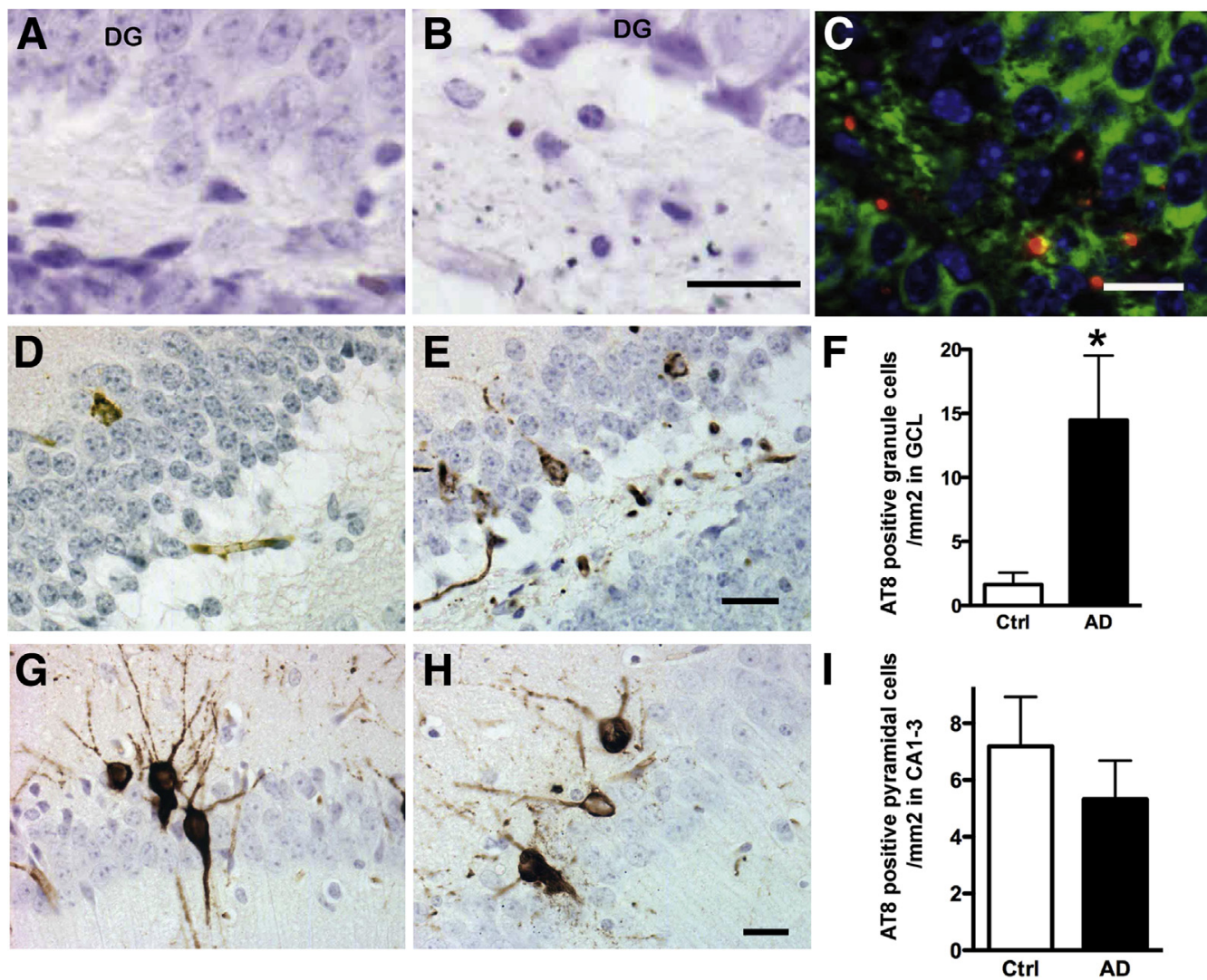

Figure 5 A-C: Human Alzheimer disease (AD) paired helical filaments (PHFs) induce formation of phosphotau-positive grains and argyrophilic grains into THY-Tau22 mice. A and B: Gallyas silver staining of brain sections at the level of the dentate gyrus (DG) of hippocampus of a THY-Tau22 mouse injected with Sarkosyl-insoluble PHF-tau from an AD case, Gallyas-positive grains are detected in the granule cell layer (GCL) and the hilus of dentate gyrus in the injected side (B) but not in the noninjected side (A). C: Double immunolabeling with the anti-human tau BR21 (green), and the phosphotau AT8 (red) antibodies. Grains are AT8 positive but human tau negative. DAPI nuclear counterstaining. D-F: Human AD PHF increase the density of AT8-positive cells in the dentate gyrus in THY-Tau22 mice. Immunolabeling with the phosphotau AT8 antibody of the gyrus dentatus on the injected side after injection of Sarkosyl-insoluble fraction from a control (Ctrl) case (D) or AD Sarkosyl-insoluble PHF (E). AT8-positive granule cells are more numerous after injection of AD Sarkosyl-insoluble PHF-tau. AT8-positive grains are present in the dentate gyrus and the hilus. Hematoxylin counterstaining. F: Quantification of the number of AT8-positive cells in the gyrus dentatus (injected side) in THY-Tau22 mice injected with Sarkosyl-insoluble tau from an AD case or Sarkosyl-insoluble fraction from a control case. The number of AT8-positive cells is significantly increased in mice injected with AD Sarkosyl-insoluble tau. G-I: Human AD PHF does not increase the density of AT8-positive cells in the CA1 to CA3 sectors in THY-Tau22 mice. Immunolabeling with the phosphotau AT8 antibody of the CA1 sector on the injected side after injection of control fraction (G) or AD Sarkosyl-insoluble PHF (H). I: Quantification of the number of AT8-positive cells in the CA1 to CA3 sectors (injected side) in THY-Tau22 mice injected with Sarkosylinsoluble fraction from an $A D$ case or from a control case. The density of AT8-positive pyramidal cells in CA1 to CA3 is not increased in mice injected with $A D$ Sarkosyl-insoluble tau. Hematoxylin counterstaining. ${ }^{*} P<0.05$ by Student's $t$-test. Scale bars: $20 \mu \mathrm{m}(\mathbf{A}-\mathbf{C}, \mathbf{G}$, and $\mathbf{H}) ; 25 \mu \mathrm{m}(\mathbf{D}$ and $\mathbf{E})$.

CHO cells and visualized by electron microscopy, consistent with previous studies showing by optical microscopy internalization of recombinant tau fibrils into C17.2 and HEK293 cells ${ }^{41,42}$ and of PHF into HEK293 cells. ${ }^{37}$ We observed that endogenous tau expressed in a clonal CHO-tau cell line also colocalized with human PHF after 24 hours, suggesting that some of it was recruited to exogenous PHF-tau after internalization of the latter. These results are consistent with results showing that only tau aggregates with a minimum size (and not monomeric tau) are internalized and seed intracellular tau aggregation. ${ }^{43,44}$ Low-molecular-weight oligomeric tau or phosphate-buffered saline soluble high-molecularweight tau species from AD brain was recently reported to be preferentially uptaken into cells but consisted of small globular and not fibrillar tau. ${ }^{12,45}$ In this study, we provide evidence that fibrillar hyperphosphorylated PHF-tau also induce significant tau pathology propagation in wild-type animals.

Stereotaxic injection of human PHF induced a tau pathology in wild-type mouse brains in the form of Gallyas silver positive and tau-positive granular inclusions, neuropil threads, and coiled bodies. These tau-positive grains exclusively composed of endogenous murine tau were labeled with antibodies to phosphorylated tau, to conformationally modified tau, to $4 \mathrm{R}$ tau, and to ubiquitin (but devoid of immunoreactivity for caspase cleaved tau or for low-molecular-weight tau oligomers). These neuropathological lesions are reminiscent of argyrophilic grain disease. Argyrophilic grain disease is a four-repeat tauopathy in which a spatial spreading of tau pathology is also observed. $^{46,47}$ The argyrophilic grains induced by stereotaxic injection of human PHF were also ubiquitin and p62 
positive, similarly to what is observed in argyrophilic grains in argyrophilic grain disease ${ }^{48,49}$ and in neuronal and glial inclusions in tauopathies. $^{50,51}$

Argyrophilic grains in human tauopathies contain only the three isoforms of $4 \mathrm{R}$ tau in the microtubule binding domain. Adult mouse neurons express only the $4 \mathrm{R}$ tau isoforms and not the six tau isoforms expressed in adult human brain, and that are present in human PHF extracted from AD cases. Seeding in mice by injection of human PHF might thus lead to recruitment only of $4 \mathrm{R}$ murine tau, and development of a 4R tau pathology, such as argyrophilic grains. The short incubation period in our model, compared to long incubation period in human diseases, might also lead to different types of tau pathology.

Because accumulation of insoluble tau was reported to decrease $26 \mathrm{~S}$ proteasome activity in vitro ${ }^{52}$ and in vivo, ${ }^{53}$ ubiquitin-positive granular structures observed by stereotaxic injection of PHF-tau may contain not only murine tau aggregates but also other proteasome substrates.

Injection of human PHF caused local atrophy in the dentate gyrus of injected side of the mouse brains. This atrophy was observed in the molecular layer, the granule cell layer, and the hilus, consistent with cell loss and/or atrophy of dendritic and axonal processes of granule cells. The mechanisms of this PHF-induced toxicity still remain unclear. PHF may directly induce toxicity, or the recruitment of endogenous murine tau may cause cellular loss of function and/or gain of toxic function, leading to this local atrophy in the injected region. A neurotoxic effect associated to seeding of tau pathology after injection was not described, ${ }^{10}$ and not found ${ }^{13}$ in previous studies, except in a recent report. ${ }^{14}$ Our results are compatible with some previous studies showing that injection of brain homogenates of various tauopathies, including $\mathrm{AD}$, induced a tau pathology in non-transgenic mice, although less efficiently than in ALZ17 mice expressing a wild-type human tau. ${ }^{11}$ Argyrophilic inclusions induced by Sarkosyl-insoluble human PHF in our study developed faster (3 months) than when using $\mathrm{AD}$ brain homogenates (6 months or more). ${ }^{11}$ This faster seeding activity was most probably because of a higher concentration in the Sarkosy-insoluble fraction of the high-molecular-weight tau species responsible for murine tau seeding. A previous study on cultured HEK-293 cells also indicated that Sarkosyl-insoluble fraction from the brain of TgP301S tau mice was enriched for seed-competent tau compared to total brain lysates. ${ }^{54}$

The microtubule-binding repeats of $\operatorname{tau}^{55}$ and hexapeptide motifs in this region ${ }^{56}$ are critical for tau aggregation into PHF. This C-terminal microtubule binding domain is almost perfectly identical between human and mouse, and both human and murine wild-type tau can be fibrillized in vitro, ${ }^{38}$ supporting the idea that tau conformation in wild-type human PHF and wild-type mouse tau are close enough to allow templating of mouse tau into tau inclusions. Brain homogenate of human P301S transgenic mouse ${ }^{10}$ and oligomeric tau ${ }^{12}$ were also reported to recruit some endogenous mouse tau.
AD brain homogenates demonstrating tau spreading in mice were reported to contain $A \beta .{ }^{11}$ Our injected insoluble PHF-tau material, however, did not contain $A B$, thus excluding the possibility that amyloid might induce the tau pathology that we observed. The presence of amyloid $A B$ might nevertheless affect the development and the type of tau pathology in human diseases and in experimental models. For instance, we and others observed that the development of NFT was greatly enhanced in mutant tau mice crossed with APP/PS1 mice. ${ }^{57}$ The tau pathology induced by human PHF in wild-type mice did not expand, however, as widely as reported in models in which human mutant P301S brain homogenates were injected in mice expressing a wild-type human $\operatorname{tau}^{10}$ or by using seeding with tau fibrils made of recombinant tau bearing the same mutation as the mutant tau expressed in these models. ${ }^{13,14,58}$ Higher conformation similarities between the injected tau species and the tau species expressed in the acceptor mouse most probably explain this higher propagation efficiency.

Injection of human AD PHF led to formation of granular argyrophilic tau lesions in both wild-type and THY-Tau22 mice, and the extent of grain development was similar in the two genotypes. The grain themselves, however, were mainly composed of murine tau and not of human double mutant tau in THY-Tau22 mice. Injection of human AD PHF increased locally the density of phosphotau-positive granule cells in the dentate gyrus, but this was not associated to increased Gallyas-positive cells in this cell layer. The inability of injected human AD PHF to seed efficiently aggregation of human G272V/P301S mutant tau in THYTau22 mice suggest that the conformation of G272V/P301S mutant tau is significantly different from tau conformation in wild-type human PHF. We previously observed that NFT and Sarkosyl-insoluble tau in G272V/P301S mutant tau mice $(\operatorname{Tg} 30)$ have limited content of wild-type endogenous murine tau, ${ }^{28}$ indicating that $\mathrm{G} 272 \mathrm{~V} / \mathrm{P} 301 \mathrm{~S}$ mutant tau also does not efficiently seed wild-type murine tau. Interestingly, in human MAPT P301L brains, NFTs were exclusively composed of P301L tau devoid of nonmutant tau. ${ }^{59} \mathrm{P} 301 \mathrm{~L}$ mutation is located in the microtubule repeat region (R2), whereas another mutation outside of MTBR (R406W) recruited nonmutant tau into Sarkosyl-insoluble fraction. ${ }^{59}$ Fibrillogenic nuclei made of P301L tau enhanced the assembly of P301L tau into filaments but not of wild-type tau. ${ }^{60}$ Similarly, THY-Tau22 mice express a human tau with two mutations in the microtubule repeat region (P301S) (R2) and G272V (R1) that might interfere with templating of wild-type tau. Stereotaxic hippocampal injection of wild-type recombinant fibrils (repeat domain) was also reported to induce a limited tau pathology in P301L mice contrary to recombinant fibrils (repeat domain) bearing the P301L mutation. ${ }^{61}$

The mice injected with Sarkosyl-insoluble tau had no deficits in working memory and spatial recognition assessed by spontaneous alternation in a Y-maze test. Although these mice had a significant atrophy in the dentate gyrus of the 
injected side, it was not sufficient to cause a deficit in working memory.

In conclusion, our data indicate that human AD PHF had a better efficiency to initiate seeding of wild-type murine tau than of double mutant human tau (G272V/P301S) overexpressed in THY-Tau22 mouse brains. Altogether, these data suggest the existence of conformation barriers between some mutant tau and wild-type tau for tau seeding in vivo. Recent studies have shown that tau molecular species seed in a prion-like strain properties ${ }^{1,62}$ and conformation barriers might play a role in the definition of these tau strains, and need to be taken into account when designing and analyzing tau spreading models in vivo. Our results also point to the interest of a wild-type model in which the study of tau spreading, and how to interfere with it, is not dependent of the artificial expression of a mutant tau protein, in which cell autonomous and cell nonautonomous mechanisms of propagation of tau pathology are less easy to disentangle.

\section{Acknowledgments}

We thank Dr. Peter Davies for providing PHF1, MC1, and Alz50 antibodies, Dr. Rakez Kayed for T22 antibody, Drs. Masato Hasegawa and Michel Goedert for AP422 antibody, and Dr. Marc Mercken for mTau5 antibody.

\section{Supplemental Data}

Supplemental material for this article can be found at http://dx.doi.org/10.1016/j.ajpath.2016.06.008.

\section{References}

1. Holtzman DM, Morris JC, Goate AM: Alzheimer's disease: the challenge of the second century. Sci Transl Med 2011, 3:77sr71

2. Buee L, Bussiere T, Buee-Scherrer V, Delacourte A, Hof PR: Tau protein isoforms, phosphorylation and role in neurodegenerative disorders. Brain Res Brain Res Rev 2000, 33:95-130

3. Ballatore C, Lee VM, Trojanowski JQ: Tau-mediated neurodegeneration in Alzheimer's disease and related disorders. Nat Rev Neurosci 2007, 8:663-672

4. Wang Y, Mandelkow E: Tau in physiology and pathology. Nat Rev Neurosci 2016, 17:22-35

5. Frost B, Gotz J, Feany MB: Connecting the dots between tau dysfunction and neurodegeneration. Trends Cell Biol 2015, 25: $46-53$

6. Braak H, Del Tredici K: The pathological process underlying Alzheimer's disease in individuals under thirty. Acta Neuropathol 2011, 121:171-181

7. Braak E, Braak H, Mandelkow EM: A sequence of cytoskeleton changes related to the formation of neurofibrillary tangles and neuropil threads. Acta Neuropathol 1994, 87:554-567

8. Delacourte A, David JP, Sergeant N, Buee L, Wattez A, Vermersch P, Ghozali F, Fallet-Bianco C, Pasquier F, Lebert F, Petit H, Di Menza C: The biochemical pathway of neurofibrillary degeneration in aging and Alzheimer's disease. Neurology 1999, 52:1158-1165

9. van den Bosch de Aguilar P, Langhendries-Weverberg C, GoemaereVanneste J, Flament-Durand J, Brion JP, Couck AM: Transplantation of human cortex with Alzheimer's disease into rat occipital cortex: a model for the study of Alzheimer disease. Experientia 1984, 40: 402-403

10. Clavaguera F, Bolmont T, Crowther RA, Abramowski D, Frank S, Probst A, Fraser G, Stalder AK, Beibel M, Staufenbiel M, Jucker M, Goedert M, Tolnay M: Transmission and spreading of tauopathy in transgenic mouse brain. Nat Cell Biol 2009, 11:909-913

11. Clavaguera F, Akatsu H, Fraser G, Crowther RA, Frank S, Hench J, Probst A, Winkler DT, Reichwald J, Staufenbiel M, Ghetti B, Goedert M, Tolnay M: Brain homogenates from human tauopathies induce tau inclusions in mouse brain. Proc Natl Acad Sci U S A 2013, 110:9535-9540

12. Lasagna-Reeves CA, Castillo-Carranza DL, Sengupta U, GuerreroMunoz MJ, Kiritoshi T, Neugebauer V, Jackson GR, Kayed R: Alzheimer brain-derived tau oligomers propagate pathology from endogenous tau. Sci Rep 2012, 2:700

13. Iba M, Guo JL, McBride JD, Zhang B, Trojanowski JQ, Lee VM: Synthetic tau fibrils mediate transmission of neurofibrillary tangles in a transgenic mouse model of Alzheimer's-like tauopathy. J Neurosci 2013, 33:1024-1037

14. Peeraer E, Bottelbergs A, Van Kolen K, Stancu IC, Vasconcelos B, Mahieu M, Duytschaever H, Ver Donck L, Torremans A, Sluydts E, Van Acker N, Kemp JA, Mercken M, Brunden KR, Trojanowski JQ, Dewachter I, Lee VM, Moechars D: Intracerebral injection of preformed synthetic tau fibrils initiates widespread tauopathy and neuronal loss in the brains of tau transgenic mice. Neurobiol Dis 2015, 73:83-95

15. de Calignon A, Polydoro M, Suarez-Calvet M, William C, Adamowicz DH, Kopeikina KJ, Pitstick R, Sahara N, Ashe KH, Carlson GA, Spires-Jones TL, Hyman BT: Propagation of tau pathology in a model of early Alzheimer's disease. Neuron 2012, 73:685-697

16. Liu L, Drouet V, Wu JW, Witter MP, Small SA, Clelland C, Duff K Trans-synaptic spread of tau pathology in vivo. PLoS One 2012, 7: e31302

17. Dujardin S, Lecolle $\mathrm{K}$, Caillierez $\mathrm{R}$, Begard $\mathrm{S}$, Zommer $\mathrm{N}$, Lachaud C, Carrier S, Dufour N, Auregan G, Winderickx J, Hantraye P, Deglon N, Colin M, Buee L: Neuron-to-neuron wild-type Tau protein transfer through a trans-synaptic mechanism: relevance to sporadic tauopathies. Acta Neuropathol Commun 2014, 2:14

18. Schindowski K, Bretteville A, Leroy K, Begard S, Brion JP, Hamdane M, Buee L: Alzheimer's disease-like tau neuropathology leads to memory deficits and loss of functional synapses in a novel mutated tau transgenic mouse without any motor deficits. Am J Pathol 2006, 169:599-616

19. Greenberg SG, Davies P: A preparation of Alzheimer paired helical filaments that displays distinct tau proteins by polyacrylamide gel electrophoresis. Proc Natl Acad Sci U S A 1990, $87: 5827-5831$

20. Brion JP, Hanger DP, Bruce MT, Couck AM, Flament-Durand J, Anderton BH: Tau in Alzheimer neurofibrillary tangles: N- and Cterminal regions are differentially associated with paired helical filaments and the location of a putative abnormal phosphorylation site Biochem J 1991, 273:127-133

21. Ando K, Kabova A, Stygelbout V, Leroy K, Heraud C, Frederick C, Suain V, Yilmaz Z, Authelet M, Dedecker R, Potier MC, Duyckaerts C, Brion JP: Vaccination with sarkosyl insoluble PHF-tau decrease neurofibrillary tangles formation in aged tau transgenic mouse model: a pilot study. J Alzheimers Dis 2014, 40:S135-S145

22. Brion JP, Hanger DP, Couck AM, Anderton BH: A68 proteins in Alzheimer's disease are composed of several tau isoforms in a phosphorylated state which affects their electrophoretic mobilities. Biochem J 1991, 279(Pt 3):831-836

23. Boom A, Authelet M, Dedecker R, Frederick C, Van Heurck R, Daubie V, Leroy K, Pochet R, Brion JP: Bimodal modulation of tau protein phosphorylation and conformation by extracellular $\mathrm{Zn} 2+$ in human-tau transfected cells. Biochim Biophys Acta 2009, 1793: $1058-1067$ 
24. Morel M, Authelet M, Dedecker R, Brion JP: Glycogen synthase kinase-3beta and the p25 activator of cyclin dependent kinase 5 increase pausing of mitochondria in neurons. Neuroscience 2010, 167: 1044-1056

25. Leroy K, Bretteville A, Schindowski K, Gilissen E, Authelet M, De Decker R, Yilmaz Z, Buee L, Brion JP: Early axonopathy preceding neurofibrillary tangles in mutant tau transgenic mice. Am J Pathol 2007, 171:976-992

26. Leroy K, Ando K, Heraud C, Yilmaz Z, Authelet M, Boeynaems JM, Buee L, De Decker R, Brion JP: Lithium treatment arrests the development of neurofibrillary tangles in mutant tau transgenic mice with advanced neurofibrillary pathology. J Alzheimers Dis 2010, 19: 705-719

27. Holcomb LA, Gordon MN, Jantzen P, Hsiao K, Duff K, Morgan D: Behavioral changes in transgenic mice expressing both amyloid precursor protein and presenilin-1 mutations: lack of association with amyloid deposits. Behav Genet 1999, 29:177-185

28. Ando K, Leroy K, Heraud C, Yilmaz Z, Authelet M, Suain V, De Decker R, Brion JP: Accelerated human mutant tau aggregation by knocking out murine tau in a transgenic mouse model. Am J Pathol 2011, 178:803-816

29. Sennvik K, Boekhoorn K, Lasrado R, Terwel D, Verhaeghe S, Korr H, Schmitz C, Tomiyama T, Mori H, Krugers H, Joels M, Ramakers GJ, Lucassen PJ, Van Leuven F: Tau-4R suppresses proliferation and promotes neuronal differentiation in the hippocampus of tau knockin/knockout mice. FASEB J 2007, 21:2149-2161

30. Goedert M, Jakes R, Vanmechelen E: Monoclonal antibody AT8 recognises tau protein phosphorylated at both serine 202 and threonine 205. Neurosci Lett 1995, 189:167-169

31. Goedert M, Jakes R, Crowther RA, Cohen P, Vanmechelen E, Vandermeeren M, Cras P: Epitope mapping of monoclonal antibodies to the paired helical filaments of Alzheimer's disease: identification of phosphorylation sites in tau protein. Biochem J 1994, 301:871-877

32. Otvos L Jr, Feiner L, Lang E, Szendrei GI, Goedert M, Lee VM: Monoclonal antibody PHF-1 recognizes tau protein phosphorylated at serine residues 396 and 404. J Neurosci Res 1994, 39:669-673

33. Hasegawa M, Jakes R, Crowther RA, Lee VM, Ihara Y, Goedert M: Characterization of $\mathrm{mAb} \mathrm{AP} 422$, a novel phosphorylation-dependent monoclonal antibody against tau protein. FEBS Lett 1996, 384: $25-30$

34. Jicha GA, Bowser R, Kazam IG, Davies P: Alz-50 and MC-1, a new monoclonal antibody raised to paired helical filaments, recognize conformational epitopes on recombinant tau. J Neurosci Res 1997, 48:128-132

35. Brion JP, Guilleminot J, Couchie D, Flament-Durand J, Nunez J: Both adult and juvenile tau microtubule-associated proteins are axon specific in the developing and adult rat cerebellum. Neuroscience 1988, 25:139-146

36. Lasagna-Reeves CA, Castillo-Carranza DL, Sengupta U, Sarmiento J, Troncoso J, Jackson GR, Kayed R: Identification of oligomers at early stages of tau aggregation in Alzheimer's disease. FASEB $\mathrm{J}$ 2012, 26:1946-1959

37. Santa-Maria I, Varghese M, Ksiezak-Reding H, Dzhun A, Wang J, Pasinetti GM: Paired helical filaments from Alzheimer disease brain induce intracellular accumulation of Tau protein in aggresomes. J Biol Chem 2012, 287:20522-20533

38. Kampers T, Pangalos M, Geerts H, Wiech H, Mandelkow E: Assembly of paired helical filaments from mouse tau: implications for the neurofibrillary pathology in transgenic mouse models for Alzheimer's disease. FEBS Lett 1999, 451:39-44

39. Hanger DP, Anderton BH, Noble W: Tau phosphorylation: the therapeutic challenge for neurodegenerative disease. Trends Mol Med 2009, 15:112-119

40. Martin L, Latypova X, Terro F: Post-translational modifications of tau protein: implications for Alzheimer's disease. Neurochem Int 2011, $58: 458-471$
41. Frost B, Jacks RL, Diamond MI: Propagation of tau misfolding from the outside to the inside of a cell. J Biol Chem 2009, 284: $12845-12852$

42. Holmes BB, DeVos SL, Kfoury N, Li M, Jacks R, Yanamandra K, Ouidja MO, Brodsky FM, Marasa J, Bagchi DP, Kotzbauer PT, Miller TM, Papy-Garcia D, Diamond MI: Heparan sulfate proteoglycans mediate internalization and propagation of specific proteopathic seeds. Proc Natl Acad Sci U S A 2013, 110: E3138-E3147

43. Mirbaha H, Holmes BB, Sanders DW, Bieschke J, Diamond MI: Tau trimers are the minimal propagation unit spontaneously internalized to seed intracellular aggregation. J Biol Chem 2015, 290: 14893-14903

44. Wu JW, Herman M, Liu L, Simoes S, Acker CM, Figueroa H, Steinberg J, Margittai M, Kayed R, Zurzolo C, Di Paolo G, Duff KE: Small misfolded Tau species are internalized via bulk endocytosis and anterogradely and retrogradely transported in neurons. J Biol Chem 2013, 288:1856-1870

45. Takeda S, Wegmann S, Cho H, DeVos SL, Commins C, Roe AD, Nicholls SB, Carlson GA, Pitstick R, Nobuhara CK, Costantino I, Frosch MP, Muller DJ, Irimia D, Hyman BT: Neuronal uptake and propagation of a rare phosphorylated high-molecular-weight tau derived from Alzheimer's disease brain. Nat Commun 2015, 6: 8490

46. Saito Y, Ruberu NN, Sawabe M, Arai T, Tanaka N, Kakuta Y, Yamanouchi H, Murayama S: Staging of argyrophilic grains: an age-associated tauopathy. J Neuropathol Exp Neurol 2004, 63: 911-918

47. Tolnay M, Clavaguera F: Argyrophilic grain disease: a late-onset dementia with distinctive features among tauopathies. Neuropathology 2004, 24:269-283

48. Scott IS, Lowe JS: The ubiquitin-binding protein p62 identifies argyrophilic grain pathology with greater sensitivity than conventional silver stains. Acta Neuropathol 2007, 113:417-420

49. Ferrer I, Santpere G, van Leeuwen FW: Argyrophilic grain disease. Brain 2008, 131:1416-1432

50. Kuusisto E, Salminen A, Alafuzoff I: Ubiquitin-binding protein p62 is present in neuronal and glial inclusions in human tauopathies and synucleinopathies. Neuroreport 2001, 12:2085-2090

51. Zatloukal K, Stumptner C, Fuchsbichler A, Heid H, Schnoelzer M, Kenner L, Kleinert R, Prinz M, Aguzzi A, Denk H: p62 Is a common component of cytoplasmic inclusions in protein aggregation diseases. Am J Pathol 2002, 160:255-263

52. Keck S, Nitsch R, Grune T, Ullrich O: Proteasome inhibition by paired helical filament-tau in brains of patients with Alzheimer's disease. J Neurochem 2003, 85:115-122

53. Myeku N, Clelland CL, Emrani S, Kukushkin NV, Yu WH, Goldberg AL, Duff KE: Tau-driven 26S proteasome impairment and cognitive dysfunction can be prevented early in disease by activating cAMP-PKA signaling. Nat Med 2016, 22:46-53

54. Falcon B, Cavallini A, Angers R, Glover S, Murray TK, Barnham L, Jackson S, O'Neill MJ, Isaacs AM, Hutton ML, Szekeres PG, Goedert M, Bose S: Conformation determines the seeding potencies of native and recombinant Tau aggregates. J Biol Chem 2015, 290: $1049-1065$

55. Wille H, Drewes G, Biernat J, Mandelkow EM, Mandelkow E: Alzheimer-like paired helical filaments and antiparallel dimers formed from microtubule-associated protein tau in vitro. J Cell Biol 1992, 118:573-584

56. von Bergen M, Friedhoff P, Biernat J, Heberle J, Mandelkow EM, Mandelkow E: Assembly of tau protein into Alzheimer paired helical filaments depends on a local sequence motif ((306)VQIVYK(311)) forming beta structure. Proc Natl Acad Sci U S A 2000, 97: $5129-5134$

57. Heraud C, Goufak D, Ando K, Leroy K, Suain V, Yilmaz Z, De Decker R, Authelet M, Laporte V, Octave JN, Brion JP: Increased misfolding and truncation of tau in APP/PS1/tau 
transgenic mice compared to mutant tau mice. Neurobiol Dis 2014, 62:100-112

58. Stancu IC, Vasconcelos B, Ris L, Wang P, Villers A, Peeraer E, Buist A, Terwel D, Baatsen P, Oyelami T, Pierrot N, Casteels C, Bormans G, Kienlen-Campard P, Octave JN, Moechars D, Dewachter I: Templated misfolding of Tau by prion-like seeding along neuronal connections impairs neuronal network function and associated behavioral outcomes in Tau transgenic mice. Acta Neuropathol 2015, 129:875-894

59. Miyasaka T, Morishima-Kawashima M, Ravid R, Kamphorst W, Nagashima K, Ihara Y: Selective deposition of mutant tau in the FTDP-17 brain affected by the P301L mutation. J Neuropathol Exp Neurol 2001, 60:872-884
60. Aoyagi H, Hasegawa M, Tamaoka A: Fibrillogenic nuclei composed of P301L mutant tau induce elongation of P301L tau but not wildtype tau. J Biol Chem 2007, 282:20309-20318

61. Chakrabarty P, Hudson Iii VJ, Sacino AN, Brooks MM, D’Alton S, Lewis J, Golde TE, Giasson BI: Inefficient induction and spread of seeded tau pathology in P301L mouse model of tauopathy suggests inherent physiological barriers to transmission. Acta Neuropathol 2015, 130:303-305

62. Sanders DW, Kaufman SK, DeVos SL, Sharma AM, Mirbaha H, Li A, Barker SJ, Foley AC, Thorpe JR, Serpell LC, Miller TM, Grinberg LT, Seeley WW, Diamond MI: Distinct tau prion strains propagate in cells and mice and define different tauopathies. Neuron 2014, 82:1271-1288 